\title{
RETRACTED ARTICLE: Distinguish between the data of the Internet of Things based on abnormal audio detection and the image of athletes' human actions
}

\author{
Yinkun $\mathrm{Li}^{1} \cdot$ Anzhi Wang ${ }^{1}$ \\ Received: 11 June 2021 / Accepted: 30 July 2021 / Published online: 11 August 2021 \\ (C) The Author(s), under exclusive licence to Springer-Verlag London Ltd., part of Springer Nature 2021
}

The Editor-in-Chief and the Publisher have retracted this article because the content of this article is nonsensical. The peer review process was not carried out in accordance with the Publisher's peer review policy. The authors have not responded to correspondence regarding this retraction. The online version of this article contains the full text of the retracted article as Supplementary Information.

Supplementary Information The online version contains supplementary material available at https://doi.org/10.1007/s00779-021-01616-2. 